\title{
Evaporative cooling by water spray systems: CFD simulation, experimental validation and sensitivity analysis
}

\author{
H. Montazeri ${ }^{* 1}$, B. Blocken ${ }^{1,2}$, J.L.M. Hensen ${ }^{1}$ \\ ${ }^{1}$ Building Physics and Services, Department of the Built Environment, Eindhoven University of \\ Technology, P.O. box 513, 5600 MB Eindhoven, The Netherlands \\ ${ }^{2}$ Building Physics Section, Department of Civil Engineering, Leuven University, Kasteelpark Arenberg \\ 40 - bus 2447, 3001 Heverlee, Belgium
}

\section{Graphical abstract}

\section{CFD simulation of evaporative cooling by mist spraying systems}

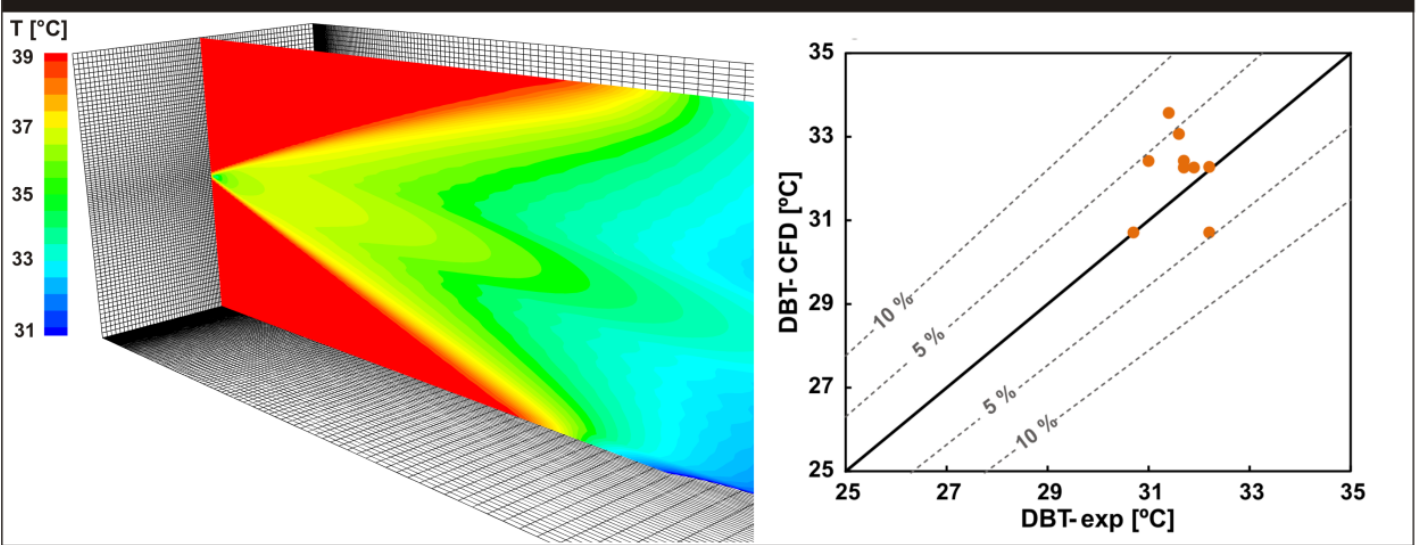

\section{Research highlights:}

- CFD simulation of evaporative cooling by mist spraying systems.

- Grid-sensitivity analysis and validation with wind-tunnel measurements.

- Lagrangian-Eulerian approach can accurately simulate the evaporation process.

- Maximum local deviations: $10 \%$ for dry bulb temperature, $5 \%$ for wet bulb temperature and $7 \%$ for specific enthalpy.

\footnotetext{
${ }^{*}$ Corresponding author: Hamid Montazeri, Building Physics and Services, Eindhoven University of Technology, P.O. box 513, 5600 MB Eindhoven, the Netherlands. Tel: +31 (0)40 247 4374, Fax: +31 (0)40 243 8595. E-mail address: h.montazeri@tue.nl
} 


\title{
Evaporative cooling by water spray systems: CFD simulation, experimental validation and sensitivity analysis
}

\author{
H. Montazeri*, ${ }^{* 1}$, B. Blocken ${ }^{1,2}$, J.L.M. Hensen ${ }^{1}$ \\ ${ }^{I}$ Building Physics and Services, Department of the Built Environment, Eindhoven University of \\ Technology, P.O. box 513, 5600 MB Eindhoven, The Netherlands \\ ${ }^{2}$ Building Physics Section, Department of Civil Engineering, Leuven University, Kasteelpark Arenberg \\ 40 - bus 2447, 3001 Heverlee, Belgium
}

\begin{abstract}
Evaporative cooling by water spray is increasingly used as an efficient and environmentally-friendly approach to enhance thermal comfort in built environments. The complex two-phase flow in a water spray system is influenced by many factors such as continuous phase velocity, temperature and relative humidity patterns, droplet characteristics and continuous phase-droplet and droplet-droplet interactions. Computational Fluid Dynamics (CFD) can be a valuable tool for assessing the potential and performance of evaporative cooling by water spray systems in outdoor and indoor urban environments. This paper presents a systematic evaluation of the Lagrangian-Eulerian approach for evaporative cooling provided by the use of a water spray system with a hollow-cone nozzle configuration. The evaluation is based on grid-sensitivity analysis and validated using wind-tunnel measurements. This paper also presents a sensitivity analysis focused on the impact of the turbulence model for the continuous phase, the drag coefficient model, the number of particle streams for the discrete phase and the nozzle spray angle. The results show that CFD simulation of evaporation by the LagrangianEulerian (3D steady RANS) approach, in spite of its limitations, can accurately predict the evaporation process, with local deviations from the wind-tunnel measurements within $10 \%$ for dry bulb temperature, $5 \%$ for wet bulb temperature and $7 \%$ for the specific enthalpy. The average deviations for all three variables are less than $3 \%$ in absolute values. The results of this paper are intended to support future CFD studies of evaporative cooling by water spray systems in outdoor and indoor urban environments.
\end{abstract}

Keywords: Computational Fluid Dynamics (CFD), Sensitivity study, Validation, Urban physics, Evaporation, Hollow-cone spray

\section{Introduction}

As a result of climate change more buildings will be exposed to milder winters and hotter summers $[1,2]$. Research indicates that a major European heat wave, such as that of 2003, will occur more frequently in the future [3] and it could become a common event by 2040 [4]. Increased heat waves and heat stress are likely to cause increased illness and death as occurred in the hot summers of 2003 and 2006 [5]. These problems are aggravated by the urban heat island effect (UHI) [6,7]. The term urban heat island is used for urban areas which exhibit higher temperatures than their rural surroundings. Therefore, adaptation strategies such as evaporative cooling need to be evaluated and implemented to reduce heat stress in the outdoor and indoor urban environment.

Several research organizations and consortia have initiated projects regarding climate change adaptation in cities as the Intergovernmental Panel on Climate Change (IPCC) has expressed the importance of adaptation measures [8]. Climate Proof Cities (CPC) is one of these research consortia investigating the climate vulnerability of urban areas and the development of climate change adaptation measures [9]. The consortium consists of universities, research institutes, policy makers and city officials to perform both basic and applied science, the latter being an integrated and thorough analysis for several locations in the Netherlands.

\footnotetext{
* Corresponding author: Hamid Montazeri, Building Physics and Services, Eindhoven University of Technology, P.O. box 513, 5600 MB Eindhoven, the Netherlands. Tel: +31 (0)40 247 4374, Fax: +31 (0)40 243 8595. E-mail address: h.montazeri@tue.nl
} 
Evaporative cooling by water spray is increasingly used as an efficient and environmentallyfriendly approach to enhance thermal comfort in urban environments (outdoors and indoors) (e.g. $[10,11])$. In a water mist spray, a cloud of very fine water droplets is produced using atomization nozzles. It enhances mixing and increases the contact surface area between the air stream and the water droplets resulting in a higher rate of evaporation yielding greater cooling of the ambient air.

For assessing the potential and performance of evaporative cooling by water spray systems in outdoor and indoor environments, different methods can be used: (i) full-scale measurements, (ii) wind-tunnel measurements, and (iii) numerical simulation with Computational Fluid Dynamics (CFD). Full-scale measurements offer the advantage that the real situation is studied and the full complexity of the problem is taken into account. However, full-scale measurements are usually only performed in a limited number of points in space. In addition, there is no or limited control over the boundary conditions. Reduced-scale wind-tunnel measurements allow a strong degree of control over the boundary conditions, however at the expense of - sometimes incompatible - similarity requirements. Furthermore, wind-tunnel measurements are usually also only performed in a limited set of points in space. CFD on the other hand provides whole-flow field data, i.e. data on the relevant parameters in all points of the computational domain [12-15]. Unlike wind-tunnel testing, CFD does not suffer from potentially incompatible similarity requirements because simulations can be conducted at full scale. CFD simulations easily allow parametric studies to evaluate alternative design configurations, especially when the different configurations are all a priori embedded within the same computational domain and grid (see e.g. [14]). However, the accuracy and reliability of CFD are of concern, and verification and validation studies are imperative (e.g. [13,16-19]). CFD is increasingly used to study a wide range of atmospheric and environmental processes (e.g. [13,20-22]). Examples include pedestrian wind comfort and wind safety around buildings [23-26], natural ventilation of buildings [12,14,27-35], air pollutant dispersion [36-39], wind-driven rain [40] and convective heat transfer [41,42]. CFD has also been used on several occasions in the past to evaluate the performance of spray systems for different applications (e.g.[43-48]). In the vast majority of these studies the Lagrangian-Eulerian (LE) approach has been used in which the continuous phase (air in this study) is represented in an Eulerian reference frame while the discrete phase (water droplets in this study) is represented in a Lagrangian reference frame. The numerical implementation of this approach was introduced and applied by O'Rourke [49,50] and Dukowicz [51] for internal combustions engine applications. However, it has been developed and used for many other applications including evaporating spray systems. A comprehensive review of the LE method including its advantages over the Eulerian-Eulerian (EE) method, modelling issues and numerical implementation is provided by Subramaniam [52].

To the best of our knowledge, a detailed evaluation of the LE approach for predicting evaporative cooling has not yet been performed. This paper presents a systematic evaluation of the LE approach for predicting evaporative cooling provided by a water spray system with hollow-cone nozzle. The evaluation is based on grid-sensitivity analysis and on validation with wind-tunnel measurements by Sureshkumar et al. [53]. This paper also presents a sensitivity analysis focused on the impact of the turbulence model for the continuous phase and the number of particle streams for the discrete phase. In addition, the important impact of nozzle spray angle is demonstrated.

The results of this paper are intended to support future CFD studies of evaporative cooling by water spray systems in outside and inside urban environments.

\section{Wind-tunnel experiments}

In the experiments by Sureshkumar et al. [53] the evaporative cooling performance of a hollow-cone nozzle spray system was investigated. The experiments were performed in an open-circuit wind-tunnel with a uniform mean wind speed. The test section of the wind tunnel was $1.9 \mathrm{~m}$ long with a cross section of $0.585 \mathrm{~m} \times 0.585 \mathrm{~m}$ (Fig. 1a). The dry-bulb temperature (DBT) and wet-bulb temperature (WBT) variations of the air stream between the inlet plane of the test section, where the spray nozzle was installed, and its outlet plane were measured for different air flow conditions and spray characteristics.

The inlet air DBT and WBT were measured by using two thermocouples placed upstream of the nozzle. Electric heaters were employed upstream of the tunnel blower to reduce the impacts of the background air temperature fluctuations. These fluctuations were limited within $\pm 0.3{ }^{\circ} \mathrm{C}$ during each set of experiments. The outlet air DBT and WBT were measured using 18 thermocouples installed at the tunnel outlet (Fig. 1b). A thermal probe installed upstream of the spray nozzle was used to measure the air stream velocity. The maximum experimental uncertainty for the mean velocity was estimated to be less than $\pm 0.05 \mathrm{~m} / \mathrm{s}$ for air velocity up to $2 \mathrm{~m} / \mathrm{s}$ and $\pm 0.2 \mathrm{~m} / \mathrm{s}$ for air velocity between 2 and $4 \mathrm{~m} / \mathrm{s}$. 
A drift eliminator with $\mathrm{z}$-shaped plates was placed close to the tunnel outlet to collect the remaining water droplets in the air flow to avoid wetting of the thermocouples. The sump water was collected in a separate tank to avoid mixing of supply and sump water in order to keep the water inlet temperature constant during each set of experiments. The inlet and outlet water temperatures were measured using two thermocouples upstream of the nozzle and downstream of the drift eliminator, respectively. Water pressure was also measured by a pressure gauge upstream of the nozzle.

In order to evaluate the impact of nozzle characteristics on cooling performance of the spray system, four identical nozzles but with different discharge openings of 3, 4, 5 and $5.5 \mathrm{~mm}$ were used. Each nozzle was installed in the middle of the test section (Fig. 1a) and designed in a way that the exiting water forms a hollow-cone sheet disintegrating into droplets. The droplet diameter distribution was determined using an image-analysing technique. The uncertainty of this technique for the mean droplet size was estimated to be $\pm 22 \%$. The half-cone angle was measured in still air and reported as a function of nozzle diameter, water pressure and background wind speed. As the exact value of the halfcone angle was not reported by Sureshkumar et al. [53], in Sec. 5.4 the influence of this parameter will be investigated. No correlations between droplet size and velocity were given by Sureshkumar et al [53].

The experiments were conducted in two periods of time to resemble different ambient (i.e. in the wind tunnel) conditions. The first set of experiments, which is used in the present study, were carried out in April-June representing a hot and dry climate condition in which DBT and humidity ratio (RH) ranged between 35 and $45{ }^{\circ} \mathrm{C}$, and 10 and $35 \%$, respectively. The second set was carried out in JulySeptember representing hot-humid conditions with ambient DBT between 25 and $40{ }^{\circ} \mathrm{C}$ and $\mathrm{RH}$ between $30 \%$ and $90 \%$. The inlet water temperature varied between 33 and $36{ }^{\circ} \mathrm{C}$ for the two ambient conditions. For each ambient condition, experiments were conducted for 36 cases; four different nozzle discharge diameters (i.e. 3, 4, 5 and $5.5 \mathrm{~mm})$, three inlet nozzle gauge pressures (1, 2 and 3 bar) and three background wind speeds $(1,2$ and $3 \mathrm{~m} / \mathrm{s})$. The three cases with a nozzle discharge diameter of 4 $\mathrm{mm}$ and a gauge pressure of 3 bar were taken since droplet size distribution data were also available for these cases.

\section{CFD simulation}

In this study the commercial software ANSYS/Fluent 12.1 [54] is used in which the LagrangianEulerian approach is implemented to simulate multi-phase flows in sprays and atomizers.

\subsection{Computational geometry and grid}

A computational model was made of the wind-tunnel test section with dimensions $0.585 \mathrm{~m} \times 0.585 \mathrm{~m}$ $\times 1.9 \mathrm{~m}$ (Fig. 2a). Geometry and grid generation was executed with the pre-processor Gambit 2.4.6, resulting in a grid with 1,018,725 hexahedral cells (Fig. 2b). A stretching ratio of 1.05 controls the cells located in the immediate surroundings of the nozzle. The grid resolution resulted from a grid-sensitivity analysis that will be outlined in section 5.1. The minimum and maximum cell volumes in the domain are approximately $1.9 \times 10^{-8} \mathrm{~m}^{3}$ and $5.9 \times 10^{-6} \mathrm{~m}^{3}$, respectively. The distance from the centre point of the wall adjacent cell to the walls is $0.006 \mathrm{~m}$. This corresponds to $\mathrm{y}^{*}$ values between 35 and 135 for the case with the maximum air inlet velocity (i.e. $3 \mathrm{~m} / \mathrm{s}$ ). As standard wall functions are used in this study, these values ensure that the centre point of the wall-adjacent cell is placed in the logarithmic region of the boundary layer.

\subsection{Boundary conditions}

In the simulations, the mean velocity inlet boundary condition for the continuous phase is a uniform profile according to the measured data $\left(=U_{\infty}\right)$. As the turbulence characteristics of the flow were not reported by Sureshkumar et al [53], a turbulence intensity, $I$, of 10\% is assumed for the inlet flow. The turbulent kinetic energy $k$ is calculated from $U_{\infty}$ and $I$ using Eq. (1). The turbulence dissipation rate, $\varepsilon$, is given by Eq. (2) where $C_{\mu}$ is a constant $(\sim 0.09)$. The turbulence length scale, $l$, in this equation is taken as $l=0.07 D_{H}$ where $D_{H}$ is the hydraulic diameter of the domain which is equal to the width of the test section $(=0.585 \mathrm{~m})$.

$$
\begin{aligned}
& k=\left(U_{\infty} \cdot I\right)^{2} \\
& \varepsilon=C_{\mu}^{3 / 4} \frac{k^{3 / 2}}{l}
\end{aligned}
$$


The thermal boundary condition at the inlet is a constant temperature. A fixed vapour mass fraction is also calculated based on the experimental data and imposed at the inlet as a boundary condition for the vapour transport equation. Note that the vapour mass fraction for the moist air can be taken as $x /(x+1)$ where $x\left(\mathrm{~kg}_{\text {vapour }} / \mathrm{kg}_{\text {dry-air }}\right)$ is the humidity ratio of air. The walls of the computational domain are modelled as no-slip walls with zero roughness height $\mathrm{k}_{\mathrm{S}}=0$. The standard wall functions [55] are applied. The adiabatic thermal boundary condition is used for these surfaces. Zero static gauge pressure is applied at the outlet plane.

Special attention is needed for the discrete phase boundary conditions to take the effect of the windtunnel walls into account. The phenomena occurring when droplets impinge on solid surfaces are complicated and depend on the physical properties of the droplets such as surface tension, viscosity, density, temperature and diameter, and on impingement conditions such as impact angle and velocity of droplets relative to the wall [56,57]. In addition, many studies were carried out to investigate the influence of wall characteristics such as roughness, temperature and wettability of the surface (e.g. [58]). A detailed review of the studies on droplet-wall impact can be found in Moreira et al. [59]. Depending on the mentioned conditions, droplets may float and be lost in a liquid film, may be reflected or may disintegrate into smaller droplets. As the temperature of the wall in the experiments by Sureshkumar et al. [53] is less than the boiling temperature and the Leidenfrost temperature of the droplets, for the simulations it is assumed that the droplets are entrained in a water film along the walls after impingement [60]. In this case, the "reflected" boundary condition is used and it is assumed that after impingement the normal momentum component is zero while the tangential component remains the same. The presence of a liquid on the surface changes the boundary condition and the impact leads to a liquid-liquid interaction. In this case, the impact characteristics depend on the surface roughness but also the film thickness compared with the droplet size [61]. However, the effect of the film thickness is not taken into account.

As mentioned in section 2, a drift eliminator was used in the experiments near the outlet plane. In this study the drift eliminator is not included in the computational domain because a detailed description of its characteristics was not reported by Sureshkumar et al. [53]. However, the impact of such plates is taken into account by using the "escape" boundary condition at the outlet, assuming that the upstream impact of the drift eliminator on the air flow pattern is negligible. By using this boundary condition, droplets leave the domain with their current conditions (i.e. velocity, temperature and vapour mass fraction at the outlet plane) and trajectory calculations are terminated [54].

\subsection{Droplet characteristics}

Geometric properties of droplets in a spray system are of the most important factors that affect the dynamic behaviour of the droplets, but also the heat and mass transfer rates between the continuous and discrete phase. These geometric properties include size and shape of the droplets. In the experiments by Sureshkumar et al. [53], an image-analysing technique was used. Fig. 3a shows the discrete number density distribution for the case that the nozzle diameter and water pressure were $3 \mathrm{~mm}$ and 4 bar, respectively. The arithmetic mean diameter, $D_{10}$, and the Sauter mean diameter, $D_{32}$, are about 198 and $293 \mu \mathrm{m}$, respectively, based on the representative drop diameters standardised by Mugele and Evans [62]:

$$
D_{p q}=\left[\frac{\int_{0}^{\infty} D^{p} f_{N}(D) d D}{\int_{0}^{\infty} D^{q} f_{N}(D) d D}\right]^{\frac{1}{p-q}}
$$

where $f_{N}(D)$ is the number density distribution and $p$ and $q$ are positive integers.

The droplet size distribution can be modelled in different ways, including semi-empirical (i.e. Rosin-Rammler [63] and Nukiyama-Tanasawa [64]), maximum entropy formalism (MEF) [65,66], discrete probability function (DPF) [67,68] and stochastic [69] models. Detailed discussions on methods for modelling drop size distribution along with their strengths and weaknesses can be found in the literature (e.g. [70,71]). The semi-empirical methods are the most common methods in which droplet size distribution is determined by fitting the measured data to pre-determined mathematical functions [70]. In the present work the Rosin-Rammler [63] model is used. This model assumes an exponential relationship between the droplet diameter, $D$, and the mass fraction of droplets with diameters greater than $D$, which can be expressed according to Eq. (4):

$$
Y_{D}=e^{-(D / \bar{D})^{n}}
$$


where $Y_{D}$ is the mass fraction of droplets with diameters greater than $D, \bar{D}$ the mean diameter and $n$ the spread parameter as an indicator of the distribution width. In this study, the following steps are taken to obtain the Rosin-Rammler distribution:

1) $Y_{D}$ is obtained from the mass density distribution $f_{M}(\mathrm{D})$. The mass density distribution is calculated using Eq. (5) in which the number density distribution $f_{\mathrm{N}}(\mathrm{D})$ is related to $f_{\mathrm{M}}(\mathrm{D})$ [72]:

$$
f_{M}(D)=\frac{N_{0} m}{M_{0}} f_{N}(D)
$$

where $N_{0}$ and $M_{0}$ are the total number and total mass of the sample droplets. In this equation, $m$ is the mass of a single droplet of diameter $D$ and density $\rho$ (i.e. $\pi \rho \mathrm{D}^{3} / 6$ ). The results are shown in Fig. $3 \mathrm{~b}$. The calculated values of $Y_{D}$ for each droplet size group are provided in Fig. 4.

2) The mean diameter, $\bar{D}$, is determined from Fig. 4 for $Y_{D}=\mathrm{e}^{-1}$ (i.e. when the droplet diameter, $D$, equals $\bar{D}$ ). For the current experimental data $\bar{D}$ is $369 \mu \mathrm{m}$.

3) The spread parameter, $n$, for each diameter group is derived from Eq. (4) (i.e. $n=\ln (-$ $\left.\left.\ln Y_{D}\right) / \ln (D / \bar{D})\right)$. Averaging over these values yields the spread parameter for the RosinRammler distribution, which is 3.67 for the current experimental data. This is within the range proposed by Lefebvre [73] for sprays, i.e. $1.5<\mathrm{n}<4$. The Rosin-Rammler curve fit is shown in Fig. 4 (solid line).

In this study, the smallest droplet diameter to be considered in the size distribution of the RosinRammler model is $74 \mu \mathrm{m}$, corresponding to the minimum resolution of the droplet measurements. The largest droplet diameter is considered $518 \mu \mathrm{m}$, based on the largest droplet diameter in the samples (Fig 3a). 20 diameters are also assumed to be injected from each droplet stream into the domain. This number was taken based on a sensitivity analysis (not shown in this paper).

The spherical drag law is used to estimate the drag coefficients acting on droplets. It assumes that the surface tension on the drop-fluid interface is strong enough to resist the tendency of the aerodynamic force to deform the drop (We $<<1$ ) (e.g. [74]). In this scenario, droplets are assumed to be non-deforming spheres and drag coefficients $\left(C_{d}\right)$, as functions of the Reynolds number $(R e)$, are estimated based on experimental drag data for solid spheres. Various correlations for the drag coefficient of spherical droplets (particles) can be found in the literature (e.g. [75-78]). In the present study the correlation by Morsi and Alexander [77] is used. This correlation proposes the following drag coefficients for a wide range of Reynolds numbers up to $5 \times 10^{4}$ :

$$
C_{d}=\frac{K_{1}}{R e}+\frac{K_{2}}{R e^{2}}+K_{3}
$$

In which $K_{l}, K_{2}$ and $K_{3}$ are three constants (Table 1).

In this study, the spray is assumed to be dilute and the impact of collision of droplets is not taken into account.

\subsection{Spray nozzle characteristics}

In this study the hollow cone spray model provided by Ansys/Fluent 12.1 [54] is used. The water droplets are injected into the computational domain from a nozzle with $4 \mathrm{~mm}$ diameter positioned in the middle of the inlet plane of the computational domain and oriented horizontally in downstream direction. The total mass flow rate and temperature of the injected water droplets are imposed according to the experimental data (Table 2). The total number of droplet (particle) streams is assumed to be 300 meaning that they are released from 300 uniformly-distributed points on the nozzle opening perimeter. In order to ensure that the results are independent of the number of droplet streams, the impact of this factor will be investigated in section 5.3. The sheet velocity, $\mathrm{U}_{0}$, is used for the initial velocity of the droplet streams. $\mathrm{U}_{0}$ is calculated as $\mathrm{C}_{\mathrm{v}}\left(2 \Delta \mathrm{P} / \rho_{\mathrm{w}}\right)^{0.5}$ where $\mathrm{C}_{\mathrm{v}}$ is the nozzle coefficient, $\Delta \mathrm{P}$ the pressure difference along the nozzle and supply pipe and $\rho_{\mathrm{w}}$ the water density. As recommended by Sureshkumar et al. [43] for the given nozzle $\mathrm{C}_{\mathrm{v}}$ is approximately 0.9 .

\subsection{Solver settings}

For the continuous phase flows, the 3D steady RANS equations for conservation of mass, momentum and energy are solved in combination with the realizable k- $\varepsilon$ turbulence model by Shih et al. [79]. The SIMPLE algorithm is used for pressure-velocity coupling, pressure interpolation is second order and 
second-order discretisation schemes are used for both the convection terms and the viscous terms of the equations.

Lagrangian trajectory simulations are performed for the discrete phase. The discrete phase interacts with the continuous phase, and the discrete phase model source terms are updated after each continuous phase iteration. To solve the equations of motion for the droplets, the Automated Tracking Scheme Selection is adopted to be able to switch between higher order lower order tracking schemes. This mechanism can improve the accuracy and stability of the simulations [52]. In this study, trapezoidal and implicit schemes are used for higher and lower order schemes, respectively. The solution of the droplet momentum, heat and mass transfer equations are solved in a fully coupled manner.

\subsection{List of cases}

Some main parameters of the three cases that are investigated in this study are given in Table 2. Case 3 is used for the sensitivity analysis.

\section{Results}

\subsection{Grid-sensitivity analysis}

A grid-sensitivity analysis was performed based on two additional grids; a coarser grid and a finer grid. An overall linear factor $\sqrt{2}$ was used for coarsening and refining. The coarse grid had 360,000 cells, while the fine grid had 2,880,000 cells. The three grids are shown in Fig. 5. The DBT profiles along three lines at the outlet plane for the three grids are compared in Fig. 6. The concept of the gridconvergence index (GCI) by Roache is also used [80] (not shown in this figure). The results show a limited dependence of the DBT results on the grid resolution in the middle of the outlet plane with a maximum local GCI value of $0.17 \%$. Negligible grid sensitivity is found for the other parts. In this case, the average discretisation error (GCI) for the lines on the left, middle and right side of the outlet plane is $0.05,0.10$ and $0.05 \%$, respectively. Therefore, the basic grid was retained for further analysis.

\subsection{Comparison of CFD results and wind-tunnel experiments}

The CFD results for the three cases in Table 2 are compared with the wind-tunnel experiments by Sureshkumar et al. [53]. The comparison is performed for the DBT, WBT and specific enthalpy values in the nine measurement points. Note that the specific enthalpy of moist air, $\mathrm{h}$, can be expressed as:

$$
h=h_{\text {dry.air }}+x \cdot h_{v}
$$

where $h_{\text {dry.air }}$ is the specific enthalpy of dry air $\left(\mathrm{kJ} / \mathrm{kg}_{\text {dry.air }}\right)$ given by $C_{p} . T$, where $C_{p}$ is the specific heat capacity of air $(\mathrm{kJ} / \mathrm{kg} \mathrm{K}) . \mathrm{x}$ is the humidity ratio $\left(\mathrm{kg}_{\text {vapour }} / \mathrm{kg}_{\text {dry.air }}\right)$ and $\mathrm{h}_{\mathrm{v}}$ the specific enthalpy of water vapour. The results in Fig. 7 shows a good agreement, within 10\% for DBT, 5\% for WBT and $7 \%$ for the specific enthalpy for all cases. The exact reasons for these deviations are not clear, but they are probably caused by a combination of limitations of the LE approach and experimental uncertainties. Apart from the LE approach limitations, the impact of collision of droplets, droplets impingement on solid surfaces and the drift eliminator on the airflow are not considered into account in this study. For the experimental uncertainties, as mentioned by Sureshkumar et al. [53], the dominant uncertainty of the experiments is for the WBT measurements. According to Eq. 7, the deviation for $\mathrm{h}$ is highly dependent on the WBT deviations rather than the one for DBT. For example, for a case with DBT $=39$ ${ }^{\circ} \mathrm{C}$ and $\mathrm{WBT}=19^{\circ} \mathrm{C}, 1^{\circ} \mathrm{C}$ of change in DBT and WBT results in about 0.06 and $6 \%$ deviations in $\mathrm{h}$, respectively. This figure also indicates that the DBT increases by increasing the inlet velocity from 1 $\mathrm{m} / \mathrm{s}$ (case 1 ) to $3 \mathrm{~m} / \mathrm{s}$ (case 3 ). The higher inlet air velocity leads to a reduction in the residence time of droplets within the domain, resulting in less time for evaporation and higher outlet DBT. Note that the initial droplet velocities for the three cases are identical. However, the inlet DBT of the air in case 1 is higher than the other cases by more than $2{ }^{\circ} \mathrm{C}$. The inlet WBT is approximately the same for the three cases (Table 2).

Fig. 8 shows the air speed (magnitude of 3D velocity), temperature and vapour mass fraction contours in the vertical centre plane. The cross-sectional profiles of these parameters along vertical lines on the centre plane of the domain are shown in Fig. 9. Both figures show that the air speed increases considerably close to the spray as the momentum lost by the droplets is obtained by the air. The liquid water concentration in the air is relatively large close to the nozzle and therefore momentum exchange is more pronounced in this area. Ghosh and Hunt [81] explains that, away from the nozzle the air and droplets behave almost independently concerning momentum exchange. In addition, from Fig. 8 and Fig. 9 the symmetric velocity, temperature and mass fraction distributions can be clearly observed close to the nozzle, which is extended until about half the length of the domain. The high 
inertia of the droplets results in symmetric trajectories of the droplets close to the nozzle. However, farther downstream the nozzle, by the decreasing momentum of the droplets, gravity becomes relatively more pronounced, resulting in a downward movement of the droplets. This leads to asymmetric distributions of speed, temperature and vapour mass fraction. The larger number of droplets is in the lower part of the domain, results in more cooling effects in this area.

Fig. 10a shows how the non-dimensional droplet mass flow rate changes along the domain. A gradual decrease of the droplet mass flow rate is clearly observed. At the outlet of the domain, more than $3 \%$ of the initial droplet mass flow has evaporated. The droplet mass flow rate is consistent with the droplet mean diameters, shown in Fig. $10 \mathrm{~b}$. It can be seen that $D_{10}$, the arithmetic mean diameter and $D_{32}$, the Sauter mean diameter decrease monotonically with increasing the distance from the inlet. As in this study the effect of droplet collision and secondary break up are not taken into account, this reduction in the mean diameters is mainly caused by the evaporation effects. The overall reduction of $D_{10}$ and $D_{32}$ within the domain is 4 and $1 \mu \mathrm{m}$, respectively.

In ANSYS/Fluent, the spray droplets are treated as parcels and each parcel includes a group of droplets, which all have the same characteristics such as temperature, diameter and speed. Fig. 11 shows the droplet (parcels) temperature and diameter distributions for three cross sections along the domain: $\mathrm{x} / \mathrm{L}=0.25,0.5$ and 0.75 . At the inlet, droplets with different diameters are injected with the same temperature, according to experimental data (Table 2). Farther downstream, the temperature of the droplets decreases considerably. This reduction is highly dependent on the droplet diameters. For example, halfway the domain $(\mathrm{x} / \mathrm{L}=0.5)$ the temperature reduction ranges from $13{ }^{\circ} \mathrm{C}$ for the smallest droplets to about $4{ }^{\circ} \mathrm{C}$ for the largest ones. Fig. 11 also shows that for $\mathrm{x} / \mathrm{L}=0.25$ and 0.5 , the temperature and diameter of the droplets with the same initial diameter change in an axisymmetric fashion. This is because of the symmetric flow field (Fig. 8) and symmetric droplet trajectories in the first half of the domain. A larger spread in the droplet temperatures can be seen at $\mathrm{x} / \mathrm{L}=0.75$, because of the asymmetric behaviour of the airflow and droplets close to the outlet. The evaporation along the domain causes the temperature of the droplets to reduce gradually and reach minimum values at the outlet of the domain.

The difference between the sensible heat at different cross sections and the one at the inlet is presented in Fig. 12, as an indication of the evaporative cooling capacity of the spray system. The cooling increases gradually along the domain and reaches to about $8 \mathrm{~kW}$ at the outlet plane. The amount of cooling is related to the sensible heat convection from/to the droplets and the latent heat of evaporation. To gain insight into the performance of the spray system, the temperature difference needed to provide the same amount of cooling (i.e. $8 \mathrm{~kW}$ ) with a sensible cooling process can be calculated using $Q=\dot{m} C_{p} \Delta T$. In this case the temperature difference is about $6.5^{\circ} \mathrm{C}$.

\subsection{Sensitivity analysis}

To analyse the sensitivity of the results to various computational and design parameters, systematic changes are made to the reference case (case 3), outlined in the previous section. In every sub-section, one of the computational and design parameters is varied, while all others are kept identical to those in the reference case.

\subsubsection{Impact of turbulence models}

3D steady RANS simulations of the continuous phase were made with five turbulence models: (1) the standard k- $\varepsilon$ model (Sk- $\varepsilon$ ) [82]; (2) the realizable k- $\varepsilon$ model (Rk- $\varepsilon$ ) [79]; (3) the renormalization Group k- $\varepsilon$ model (RNG k- $\varepsilon$ ) [83,84]; (4) the standard k- $\omega$ model (Sk- $\omega$ ) [85] and (5) the Reynolds Stress Model (RSM) [86]. For the standard $k-\omega$ model, the inlet vertical profile for $\omega$ is determined from that of $\mathrm{k}$ and $\varepsilon$ using Eq. (8), where $\mathrm{C}_{\mu}$ is equal to 0.09. For the RSM model, the Reynolds stress components are obtained from the turbulent kinetic energy k assuming isotropy of turbulence (Eqs. (9) and (10)):

$$
\begin{aligned}
& \omega=\frac{\varepsilon}{C_{\mu} k} \\
& {\overline{u_{\imath}^{\prime}}}^{2}=\frac{2}{3} k \quad(i=1,2,3) \\
& \overline{u_{\imath}^{\prime} u_{\jmath}^{\prime}}=0.0
\end{aligned}
$$


The effects of the turbulence models on the results of DBT, WBT and $h$ are shown in Fig. 13. No turbulence model can be considered superior than the others.

\subsubsection{Impact of number of particle (droplet) streams}

In ANSYS Fluent, the number of droplet streams is the number of locations along the nozzle perimeter where the parcels are injected into the computational domain. Although the injected droplet flow rate is independent of the number of streams, the less droplet streams, the lower the computational time that is required. However, a sufficiently large number of streams needs to be employed to ensure the accuracy of the results. Fig. 14 shows the influence of the number of streams on the numerical results. 10 streams lead to a high discrepancy between the CFD results and experimental data. In this case, the average deviations for DBT, WBT and $\mathrm{h}$ are 18.8, 5.1 and $6.5 \%$, respectively. By increasing the number of streams from 10 to 100 , these deviations decrease considerably and reach to $3.1,2.2$ and $2.7 \%$ respectively. For this study, approximately 100 streams are considered sufficient for CFD results that are nearly independent of the number of droplet streams.

\subsubsection{Impact of spray nozzle angle}

The impact of the spray angle is investigated by comparing the CFD results for different half-cone angles. The results are provided in Fig. 15 for the angles ranging from $16^{\circ}$ to $24^{\circ}$, according to the experimental data. An increase in the half-cone angle provides a better agreement between the experimental data and the CFD results for all parameters. Note that the exact value of the spray angle was not reported by Sureshkumar et al. [53].

\section{Discussion}

This paper has presented a detailed and systematic analysis of the Lagrangian-Eulerian approach for predicting evaporative cooling provided by a hollow-cone water spray system. It has analysed the possibilities and limitations of the LE method for assessing the performance of a water spray system. A detailed sensitivity study was performed, for the important computational parameters: grid resolution, turbulence model for the continuous phase, number of particle streams for the discrete phase, and spray nozzle angle was demonstrated. It is important to mention the main limitations of this study.

1) The comparisons have been performed based on measured air DBT and WBT at the outlet of the domain.

2) The impacts of droplet deformation and secondary breakup have not been taken into account.

3) The spray was assumed to be dilute and the impact of collision of droplets is not taken into account.

Further research is necessary to validate the performance of the LE approach in predicting droplet characteristics such as velocity, temperature and diameter. Different droplet deformation models and collision models also need to be investigated.

The validation study and sensitivity analysis provide confidence in the adopted approach and guidelines for accurate simulation of evaporative cooling by water spray systems. This is intended to support future CFD studies of evaporative cooling by water spray systems in outdoor and indoor urban environments. Future research will focus on CFD simulations of evaporative cooling as an adaptation measure for climate change in a real complex case study. For this purpose, water spray systems will be implemented near buildings and in public spaces (streets). CFD modeling will be employed to perform a parametric analysis for different air flow conditions and spray characteristics to evaluate the performance of the spray systems in mitigating the heat stress in the outdoor environment. The thermal comfort will be assessed with the Universal Thermal Climate Index (UTCI) [87].

\section{Conclusion}

This paper presents a systematic evaluation of the Lagrangian-Eulerian approach for predicting evaporative cooling provided by a water spray system. This work was motivated by lack of knowledge on the accuracy and reliability of CFD for determining evaporative cooling provided by water spray systems. The evaluation is based on a grid-sensitivity analysis and on validation with wind-tunnel measurements by Sureshkumar et al. [53].

The present study showed that CFD simulation of evaporation by using the Lagrangian-Eulerian (3D steady RANS) approach, in spite of its limitations, can accurately predict the evaporation process with an acceptable accuracy. The local deviations from the wind-tunnel measurements are within 10\% for dry bulb temperature, $5 \%$ for wet bulb temperature and $7 \%$ for the specific enthalpy. The average deviations for all three variables are less than $3 \%$ in absolute values. The impact of the turbulence 
model for the continuous phase, the number of particle streams for the discrete phase and the half-cone angle have also been investigated, and it was demonstrated that the selection of these parameters is very important for accurate and reliable results.

\section{Acknowledgements}

This research was supported by the Dutch Knowledge for Climate Research Program within the theme Climate Proof Cities (CPC).

\section{References}

[1] Van den Hurk B, Klein Tank A, Lenderink G, van Ulden A, Van Oldenborgh GJ, Katsman C, et al. KNMI climate change scenarios 2006 for the Netherlands. KNMI De Bilt; 2006.

[2] Klein Tank AMG, Lenderink G. Climate change in the Netherlands; Supplements to the KNMI'06 scenarios. Bilt K Ned Meteorol Inst 2009.

[3] Kovats RS, Hajat S. Heat stress and public health: a critical review. Annu Rev Public Health 2008;29:41-55.

[4] Stott PA, Stone DA, Allen MR. Human contribution to the European heatwave of 2003. Nature 2004;432:610-4.

[5] Fischer PH, Brunekreef B, Lebret E. Air pollution related deaths during the 2003 heat wave in the Netherlands. Atmos Environ 2004;38:1083-5.

[6] Heusinkveld BG, Steeneveld GJ, Hove LWA, Jacobs CMJ, Holtslag AAM. Spatial variability of the Rotterdam urban heat island as influenced by urban land use. J Geophys Res Atmospheres 2013.

[7] Oke TR. The energetic basis of the urban heat island. Q J R Meteorol Soc 1982;108:1-24.

[8] Parry ML. Climate Change 2007: Impacts, Adaptation and Vulnerability: Working Group II Contribution to the Fourth Assessment Report of the IPCC Intergovernmental Panel on Climate Change. vol. 4. Cambridge University Press; 2007.

[9] Albers RAW, Blocken B, Bosch PR. Overview of challenges and achievements in the Climate Proof Cities program. Build Environ 2014; this issue.

[10] Wong NH, Chong AZ. Performance evaluation of misting fans in hot and humid climate. Build Environ 2010;45:2666-78.

[11] Nishimura N, Nomura T, Iyota H, Kimoto S. Novel water facilities for creation of comfortable urban micrometeorology. Sol Energy 1998;64:197-207.

[12] Chen Q. Ventilation performance prediction for buildings: A method overview and recent applications. Build Environ 2009;44:848-58.

[13] Blocken B, Gualtieri C. Ten iterative steps for model development and evaluation applied to Computational Fluid Dynamics for Environmental Fluid Mechanics. Environ Model Softw 2012;33:1-22.

[14] Van Hooff T, Blocken B. Coupled urban wind flow and indoor natural ventilation modelling on a high-resolution grid: A case study for the Amsterdam ArenA stadium. Environ Model Softw 2010;25:51-65.

[15] Montazeri H, Blocken B. CFD simulation of wind-induced pressure coefficients on buildings with and without balconies: validation and sensitivity analysis. Build Environ 2012.

[16] Franke J, Hellsten A, Schlünzen H, Carissimo B. Best practice guideline for the CFD simulation of flows in the urban environment. vol. 732, 2007, p. 51.

[17] Tominaga Y, Mochida A, Yoshie R, Kataoka H, Nozu T, Yoshikawa M, et al. AIJ guidelines for practical applications of CFD to pedestrian wind environment around buildings. J Wind Eng Ind Aerodyn 2008;96:1749-61.

[18] Schatzmann M, Leitl B. Issues with validation of urban flow and dispersion CFD models. J Wind Eng Ind Aerodyn 2011;99:169-86.

[19] Casey M, Wintergerste T. Best Practice Guidelines: ERCOFTAC Special Interest Group on“ Quality and Trust in Industrial CFD." ERCOFTAC; 2000.

[20] Blocken B, Stathopoulos T, Carmeliet J, Hensen JL. Application of computational fluid dynamics in building performance simulation for the outdoor environment: an overview. J Build Perform Simul 2011;4:157-84.

[21] Moonen P, Defraeye T, Dorer V, Blocken B, Carmeliet J. Urban Physics: effect of the microclimate on comfort, health and energy demand. Front Archit Res 2012.

[22] Blocken B. 50 years of Computational Wind Engineering: Past, present and future. J Wind Eng Ind Aerodyn 2014:Accepted for publication. 
[23] Blocken B, Janssen WD, van Hooff T. CFD simulation for pedestrian wind comfort and wind safety in urban areas: General decision framework and case study for the Eindhoven University campus. Environ Model Softw 2012;30:15-34.

[24] He J, Song C. Evaluation of pedestrian winds in urban area by numerical approach. J Wind Eng Ind Aerodyn 1999;81:295-309.

[25] Yoshie R, Mochida A, Tominaga Y, Kataoka H, Harimoto K, Nozu T, et al. Cooperative project for CFD prediction of pedestrian wind environment in the Architectural Institute of Japan. J Wind Eng Ind Aerodyn 2007;95:1551-78.

[26] Montazeri H, Blocken B, Janssen WD, van Hooff T. CFD evaluation of new second-skin facade concept for wind comfort on building balconies: Case study for the Park Tower in Antwerp. Build Environ 2013;68:179-92.

[27] Van Hooff T, Blocken B, Aanen L, Bronsema B. A venturi-shaped roof for wind-induced natural ventilation of buildings: wind tunnel and CFD evaluation of different design configurations. Build Environ 2011;46:1797-807.

[28] Ramponi R, Blocken B. CFD simulation of cross-ventilation for a generic isolated building: impact of computational parameters. Build Environ 2012;53:34-48.

[29] Evola G, Popov V. Computational analysis of wind driven natural ventilation in buildings. Energy Build 2006;38:491-501.

[30] Jiang Y, Chen Q. Effect of fluctuating wind direction on cross natural ventilation in buildings from large eddy simulation. Build Environ 2002;37:379-86.

[31] Norton T, Grant J, Fallon R, Sun D-W. Optimising the ventilation configuration of naturally ventilated livestock buildings for improved indoor environmental homogeneity. Build Environ 2010;45:983-95.

[32] Montazeri H, Montazeri F, Azizian R, Mostafavi S. Two-sided wind catcher performance evaluation using experimental, numerical and analytical modeling. Renew Energy 2010;35:142435.

[33] Montazeri H. Experimental and numerical study on natural ventilation performance of various multi-opening wind catchers. Build Environ 2011;46:370-8.

[34] Kato S, Murakami S, Mochida A, Akabayashi S, Tominaga Y. Velocity-pressure field of cross ventilation with open windows analyzed by wind tunnel and numerical simulation. J Wind Eng Ind Aerodyn 1992;44:2575-86.

[35] Heiselberg P, Li Y, Andersen A, Bjerre M, Chen Z. Experimental and CFD evidence of multiple solutions in a naturally ventilated building. Indoor Air 2004;14:43-54.

[36] Gousseau P, Blocken B, Stathopoulos T, Van Heijst GJF. CFD simulation of near-field pollutant dispersion on a high-resolution grid: a case study by LES and RANS for a building group in downtown Montreal. Atmos Environ 2011;45:428-38.

[37] Hanna SR, Brown MJ, Camelli FE, Chan ST, Coirier WJ, Kim S, et al. Detailed simulations of atmospheric flow and dispersion in downtown Manhattan: An application of five computational fluid dynamics models. Bull Am Meteorol Soc 2006;87:1713-26.

[38] Gromke C, Buccolieri R, Di Sabatino S, Ruck B. Dispersion study in a street canyon with tree planting by means of wind tunnel and numerical investigations - Evaluation of CFD data with experimental data. Atmos Environ 2008;42:8640-50.

[39] Tominaga Y, Stathopoulos T. CFD simulation of near-field pollutant dispersion in the urban environment: A review of current modeling techniques. Atmos Environ 2013;79:716-30.

[40] Blocken B, Carmeliet J. A review of wind-driven rain research in building science. J Wind Eng Ind Aerodyn 2004;92:1079-130.

[41] Blocken B, Defraeye T, Derome D, Carmeliet J. High-resolution CFD simulations for forced convective heat transfer coefficients at the facade of a low-rise building. Build Environ 2009;44:2396-412.

[42] Allegrini J, Dorer V, Carmeliet J. Buoyant flows in street canyons: Validation of CFD simulations with wind tunnel measurements. Build Environ 2014;72:63-74.

[43] Sureshkumar R, Kale SR, Dhar PL. Heat and mass transfer processes between a water spray and ambient air-II. Simulations. Appl Therm Eng 2008;28:361-71.

[44] Kang D, Strand RK. Modeling of simultaneous heat and mass transfer within passive down-draft evaporative cooling (PDEC) towers with spray in FLUENT. Energy Build 2013;62:196-209.

[45] Li X, Zbiciński I. A sensitivity study on CFD modeling of cocurrent spray-drying process. Dry Technol 2005;23:1681-91.

[46] Saffari H, Hosseinnia SM. Two-phase Euler-Lagrange CFD simulation of evaporative cooling in a Wind Tower. Energy Build 2009;41:991-1000. 
[47] Dodge LG, Schwalb JA. Fuel spray evolution; Comparison of experiment and CFD simulation of nonevaporating spray. J Eng Gas Turbines PowerUSA 1989;111.

[48] Ahmadikia H, Moradi A, Hojjati M. Performance Analysis of a Wind-Catcher With Water Spray. Int J Green Energy 2012;9:160-73.

[49] O’Rourke PJ. Collective drop effects on vaporizing liquid sprays. Los Alamos National Lab., NM (USA); 1981.

[50] O'Rourke PJ. The KIVA computer program for multidimensional chemically reactive fluid flows with fuel sprays. Numer. Simul. Combust. Phenom., Springer; 1985, p. 74-89.

[51] Dukowicz JK. A particle-fluid numerical model for liquid sprays. J Comput Phys 1980;35:22953.

[52] Subramaniam S. Lagrangian-Eulerian methods for multiphase flows. Prog Energy Combust Sci 2013;39:215-45.

[53] Sureshkumar R, Kale SR, Dhar PL. Heat and mass transfer processes between a water spray and ambient air-I. Experimental data. Appl Therm Eng 2008;28:349-60.

[54] ANSYS Inc. ANSYS Fluent 12.0 Theory Guide. 2009.

[55] Launder BE, Spalding DB. The numerical computation of turbulent flows. Comput Methods Appl Mech Eng 1974;3:269-89.

[56] Frohn A, Roth N. Dynamics of droplets. Springer; 2000.

[57] Karl A, Frohn A. Experimental investigation of interaction processes between droplets and hot walls. Phys Fluids 2000;12:785.

[58] Roisman IV, Horvat K, Tropea C. Spray impact: rim transverse instability initiating fingering and splash, and description of a secondary spray. Phys Fluids 2006;18:102104.

[59] Moreira ALN, Moita AS, Panao MR. Advances and challenges in explaining fuel spray impingement: How much of single droplet impact research is useful? Prog Energy Combust Sci 2010;36:554-80.

[60] Anders K, Roth N, Frohn A. The velocity change of ethanol droplets during collision with a wall analysed by image processing. Exp Fluids 1993;15:91-6.

[61] Tropea C, Marengo M. The impact of drops on walls and films. Multiph Sci Technol 1999;11.

[62] Mugele RA, Evans HD. Droplet size distribution in sprays. Ind Eng Chem 1951;43:1317-24.

[63] Rosin P, Rammler E. The Laws Governing the Fineness of Powdered Coal. J Inst Fuel 1933;31:29-36.

[64] Nukiyama S, Tanasawa, Y. Experiments on the atomization of liquids in an air stream 1939.

[65] Sellens RW, Brzustowski TA. A prediction of the drop size distribution in a spray from first principles. At Spray Technol 1985;1:89-102.

[66] Xianguo L, Tankino RS. Droplet size distribution: A derivation of a Nukiyama-Tanasawa type distribution function. Combust Sci Technol 1987;56:65-76.

[67] Sovani SD, Sojka PE, Sivathanu YR. Prediction of drop size distribution from first principles: The influence of fluctuations in relative velocity and liquid physical properties. At Sprays 1999;9:133-52.

[68] Sovani SD, Sojka PE, Sivathanu YR. Prediction of drop size distribution from first principles: Joint PDF effects. At Sprays 2000;10:587-602.

[69] Apte SV, Gorokhovski M, Moin P. LES of atomizing spray with stochastic modeling of secondary breakup. Int J Multiph Flow 2003;29:1503-22.

[70] Ashgriz N. Handbook of atomization and sprays: theory and applications. Springer; 2011.

[71] Babinsky E, Sojka PE. Modeling drop size distributions. Prog Energy Combust Sci 2002;28:30329.

[72] Fan L-S, Zhu C. Principles of gas-solid flows. Cambridge University Press; 2005.

[73] Lefebvre AH. Properties of sprays. Part Part Syst Charact 1989;6:176-86.

[74] Amsden AA, Orourke PJ, Butler TD. KIVA-2: A computer program for chemically reactive flows with sprays. NASA STIrecon Tech Rep N 1989;89:27975.

[75] Khan AR, Richardson JF. The Resistance to Motion of a Solid Sphere in a Fluid. Chem Eng Commun 1987;62:135-50.

[76] Haider A, Levenspiel O. Drag coefficient and terminal velocity of spherical and nonspherical particles. Powder Technol 1989;58:63-70.

[77] Morsi SA, Alexander AJ. An investigation of particle trajectories in two-phase flow systems. J Fluid Mech 1972;55:193-208.

[78] Kelbaliyev G, Ceylan K. Development of new empirical equations for estimation of drag coefficient, shape deformation, and rising velocity of gas bubbles or liquid drops. Chem Eng Commun 2007;194:1623-37. 
[79] Shih T-H, Liou WW, Shabbir A, Yang Z, Zhu J. A new k-€ eddy viscosity model for high reynolds number turbulent flows. Comput Fluids 1995;24:227-38.

[80] Roache PJ. Perspective: a method for uniform reporting of grid refinement studies. J Fluids Eng 1994;116:405-13.

[81] Ghosh S, Hunt JCR. Induced air velocity within droplet driven sprays. Proc R Soc Lond Ser Math Phys Sci 1994;444:105-27.

[82] Jones WP, Launder BE. The prediction of laminarization with a two-equation model of turbulence. Int J Heat Mass Transf 1972;15:301-14.

[83] Yakhot V, Orszag SA, Thangam S, Gatski TB, Speziale CG. Development of turbulence models for shear flows by a double expansion technique. Phys Fluids Fluid Dyn 1992;4:1510.

[84] Choudhury D. Introduction to the renormalization group method and turbulence modeling. Fluent Incorporated; 1993.

[85] Wilcox DC. Turbulence modeling for CFD. vol. 2. DCW industries La Canada; 1998.

[86] Launder BE, Reece GJ, Rodi W. Progress in the development of a Reynolds-stress turbulence closure. J Fluid Mech 1975;68:537-66.

[87] Bröde P, Fiala D, B \lażejczyk K, Holmér I, Jendritzky G, Kampmann B, et al. Deriving the operational procedure for the Universal Thermal Climate Index (UTCI). Int J Biometeorol 2012;56:481-94. 


\section{FIGURES}

a

b

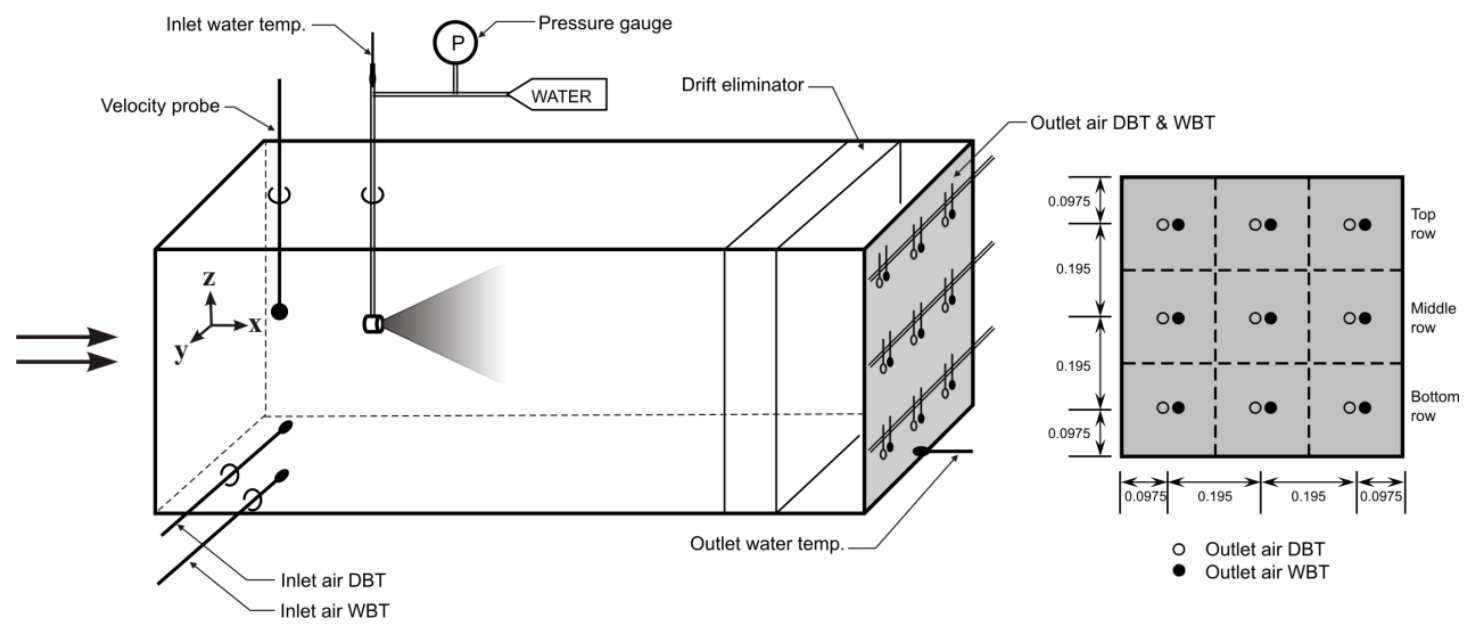

Figure 1. (a, b) Wind-tunnel measurement setup with measurement positions in the outlet plane (modified from [53]). Dimensions in meter.
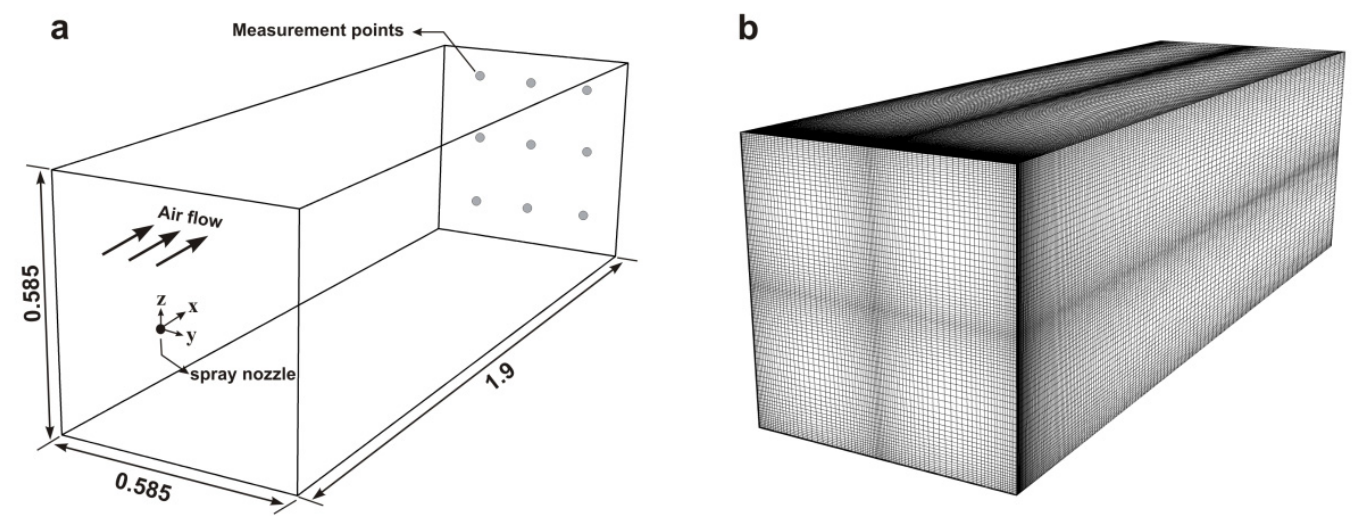

Figure 2. (a) Computational domain (dimensions in meter). (b) Computational grid (1,018,725 cells). 

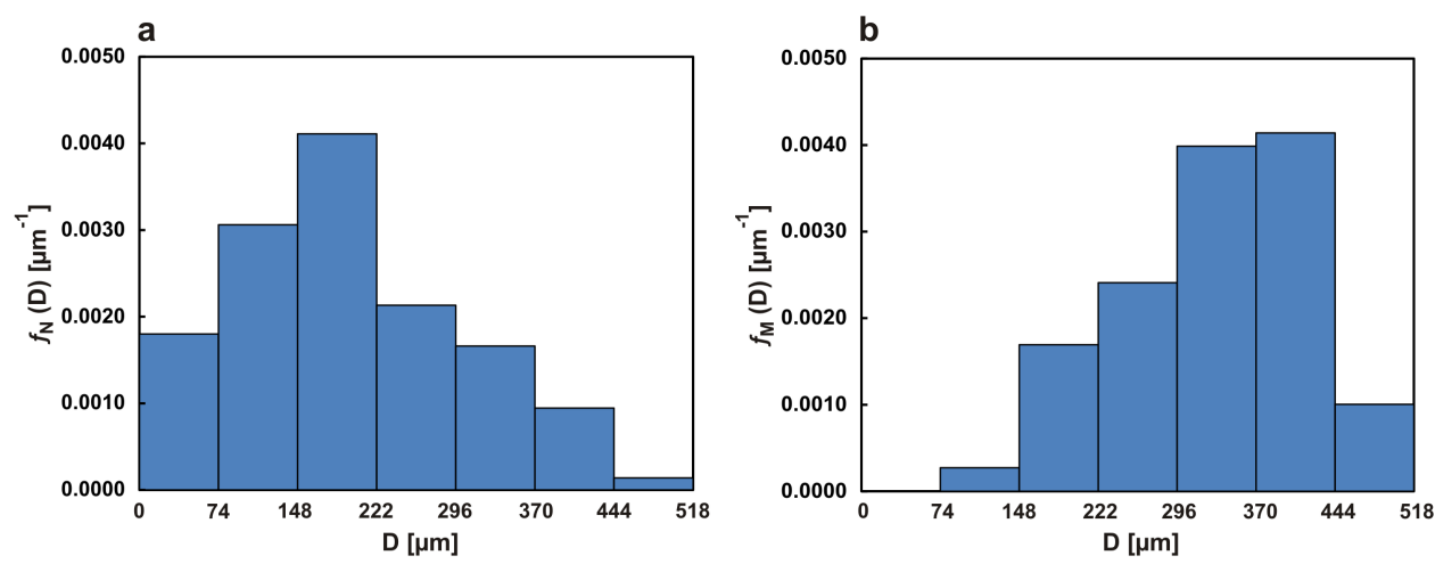

Figure 3. (a) Discrete number density distribution for the case with nozzle diameter of $3 \mathrm{~mm}$ and water pressure of 4 bar [53]. (b) Mass density distribution obtained from Eq. (5).

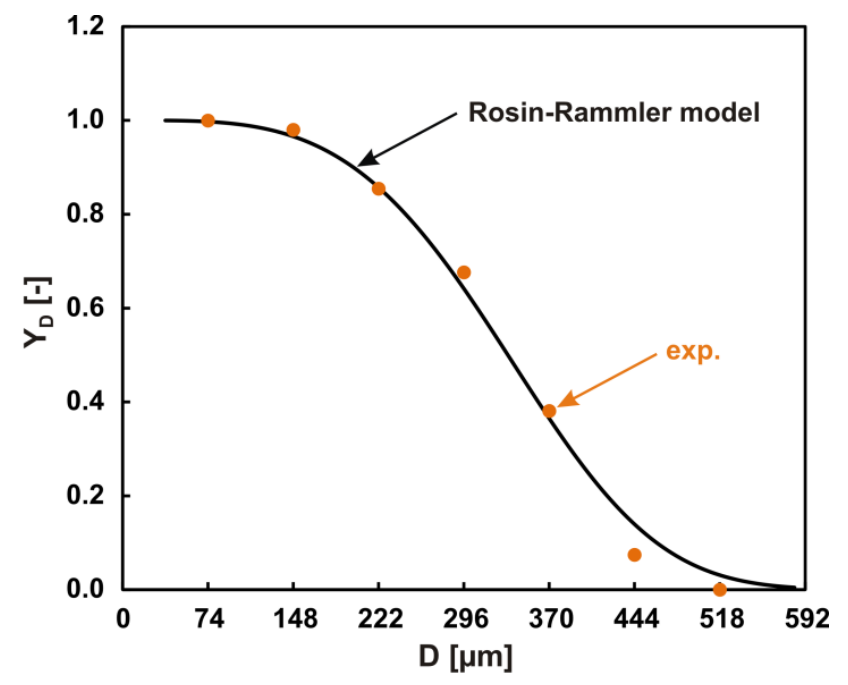

Figure 4. Rosin-Rammler curve fit (solid line) and experimental data of $Y_{D}$ (dots).

a

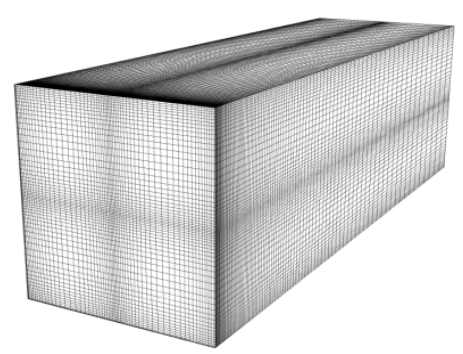

b

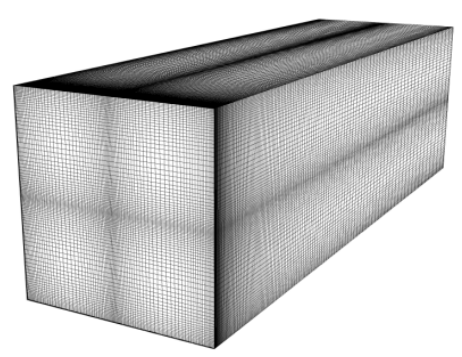

C

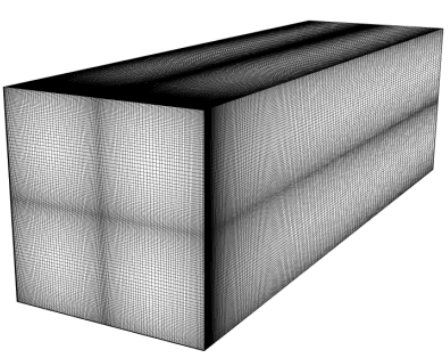

Figure 5. Computational grids for grid-sensitivity analysis. (a) Coarse grid (360,000 cells); (b) basic grid $(1,018,725$ cells) and (c) fine grid $(2,880,000$ cells). 

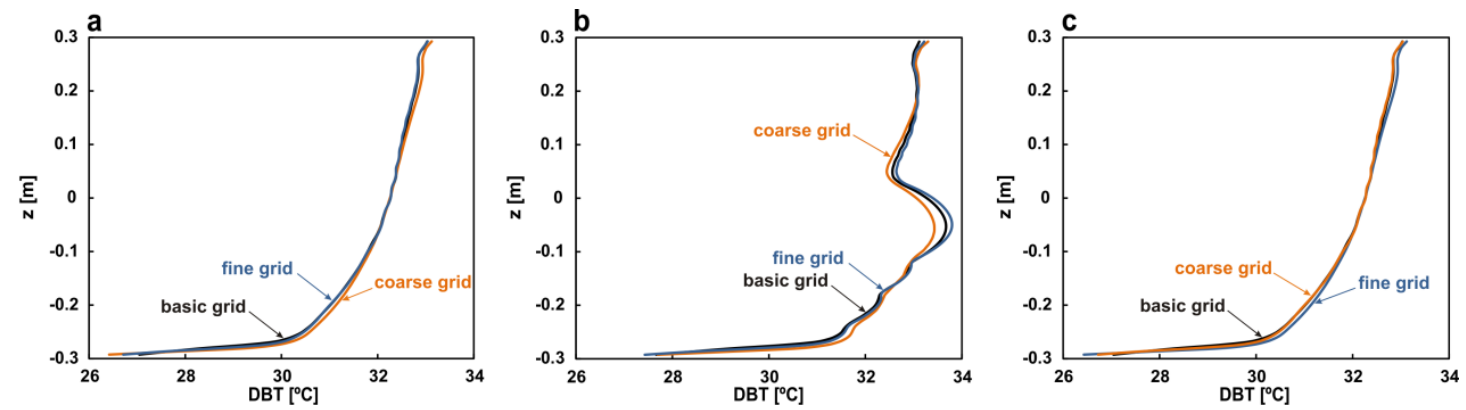

Figure 6. Results for grid-sensitivity analysis: DBT values along vertical lines (a) left, (b) middle and (c) right side of outlet plane for three grids.
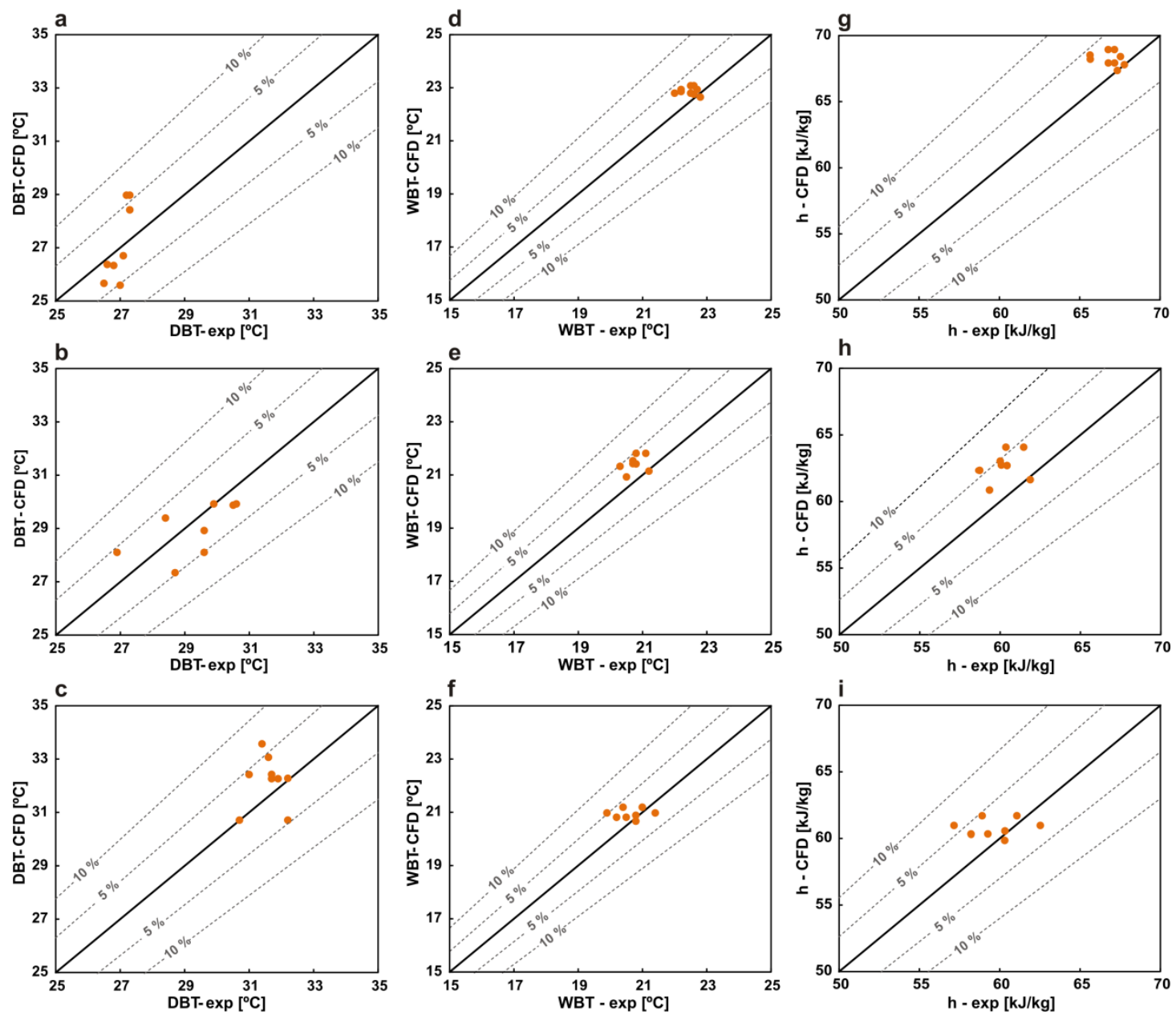

Figure 7. Comparison of calculated (CFD) and measured (exp. [53]) (a-c) DBT, (b-f) WBT and (g-i) specific enthalpy for case 1,2 and 3 , respectively. 

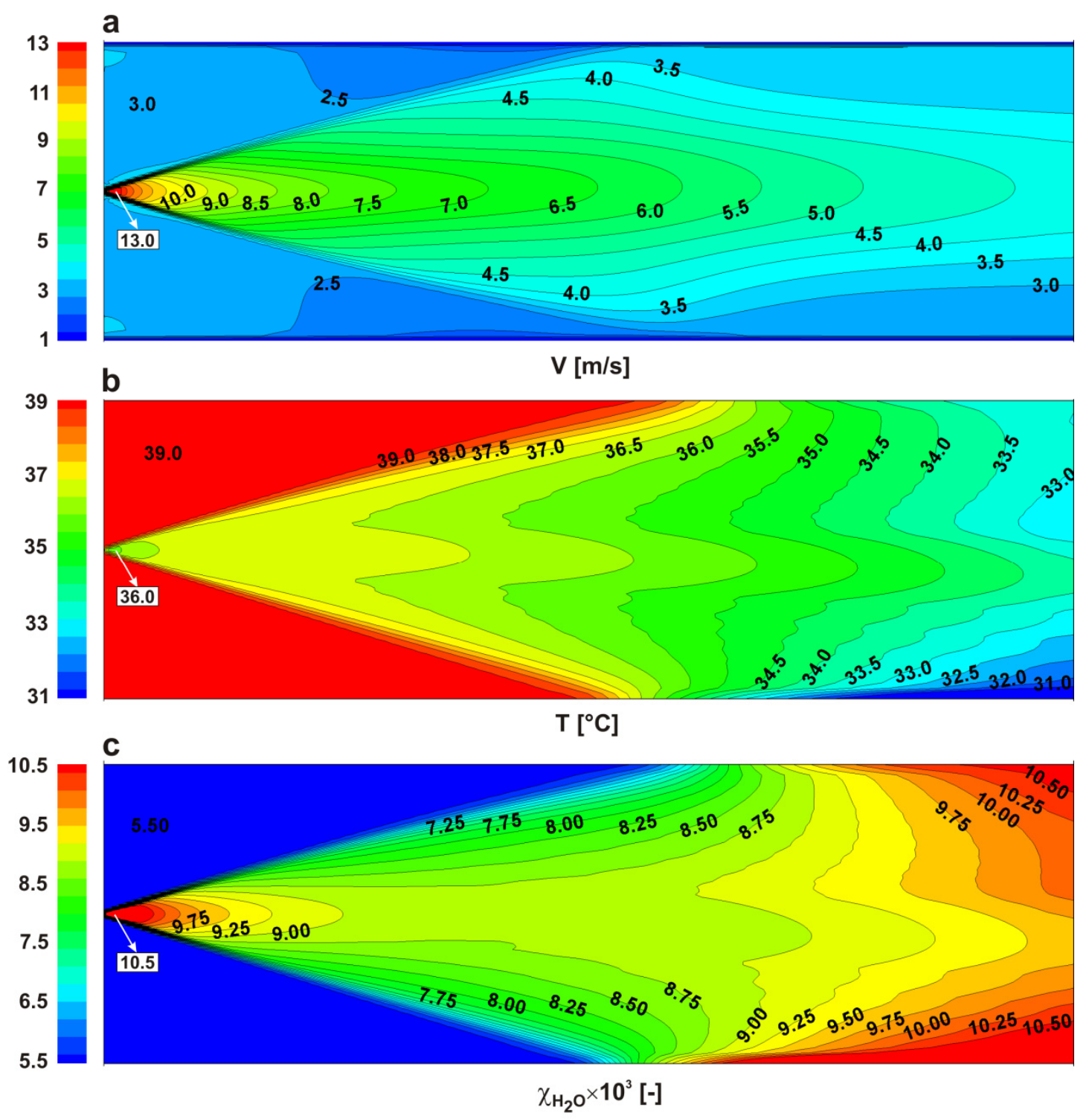

Figure 8. (a) Air velocity; (b) temperature and (c) vapour mass fraction distribution in cross-section (centre plane) for case 3 . 
a

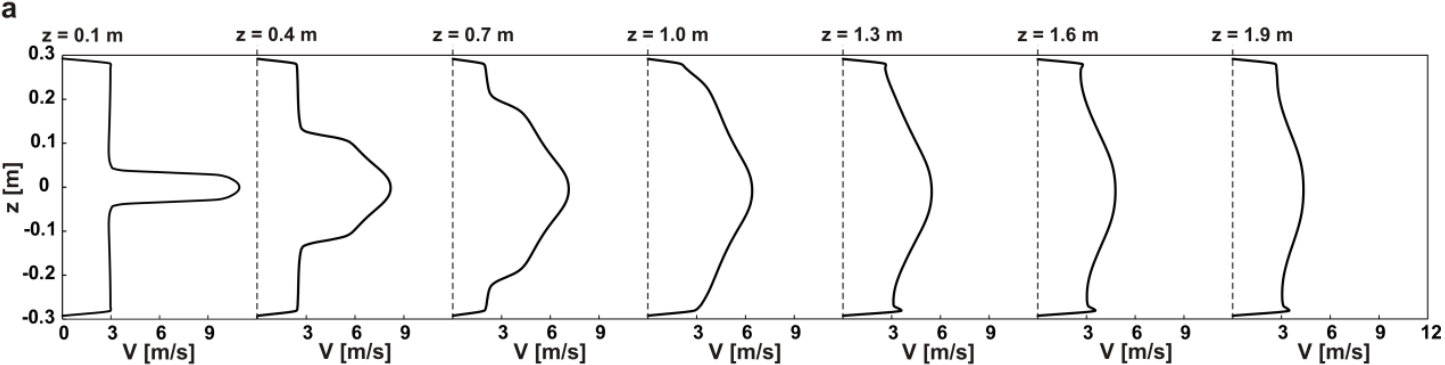

b
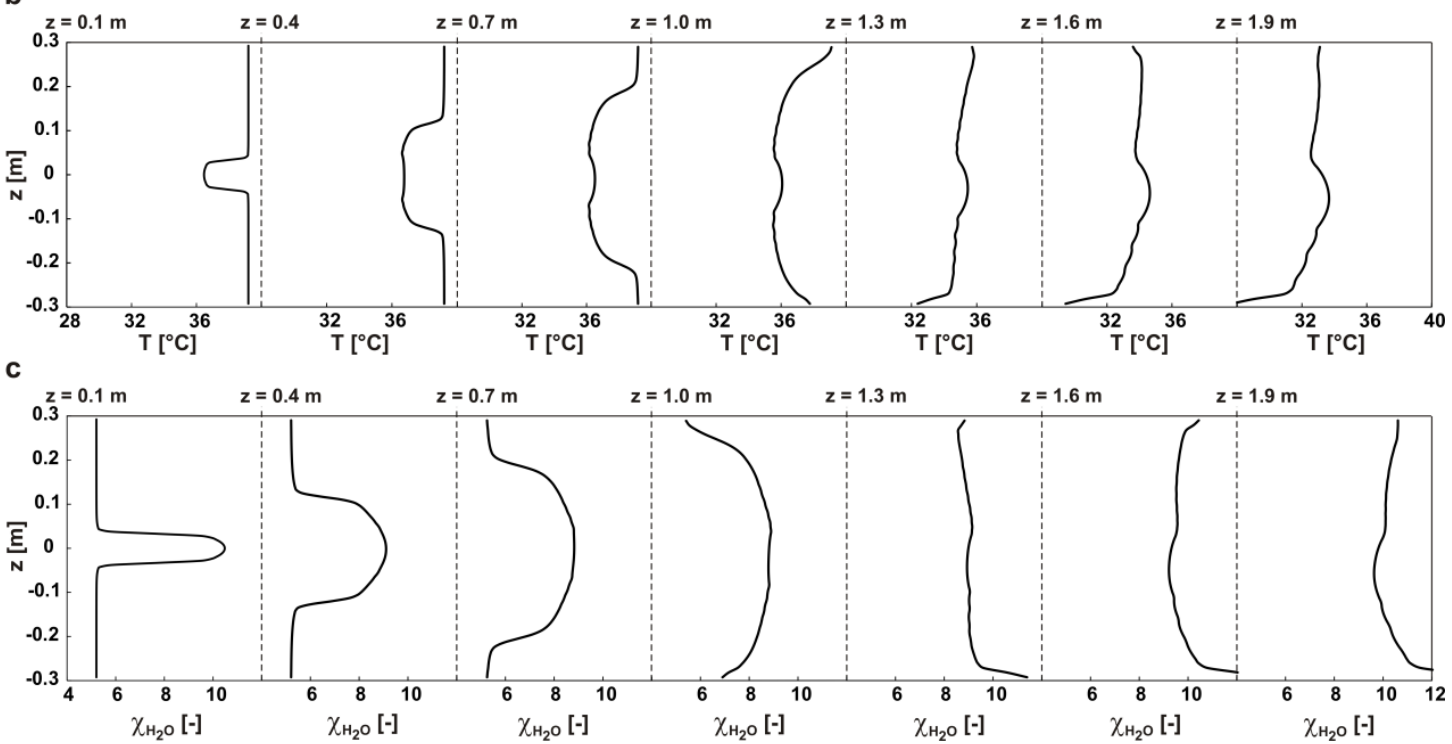

Figure 9. (a) Air speed; (b) temperature and (c) vapour mass fraction along vertical lines in the centre plane.
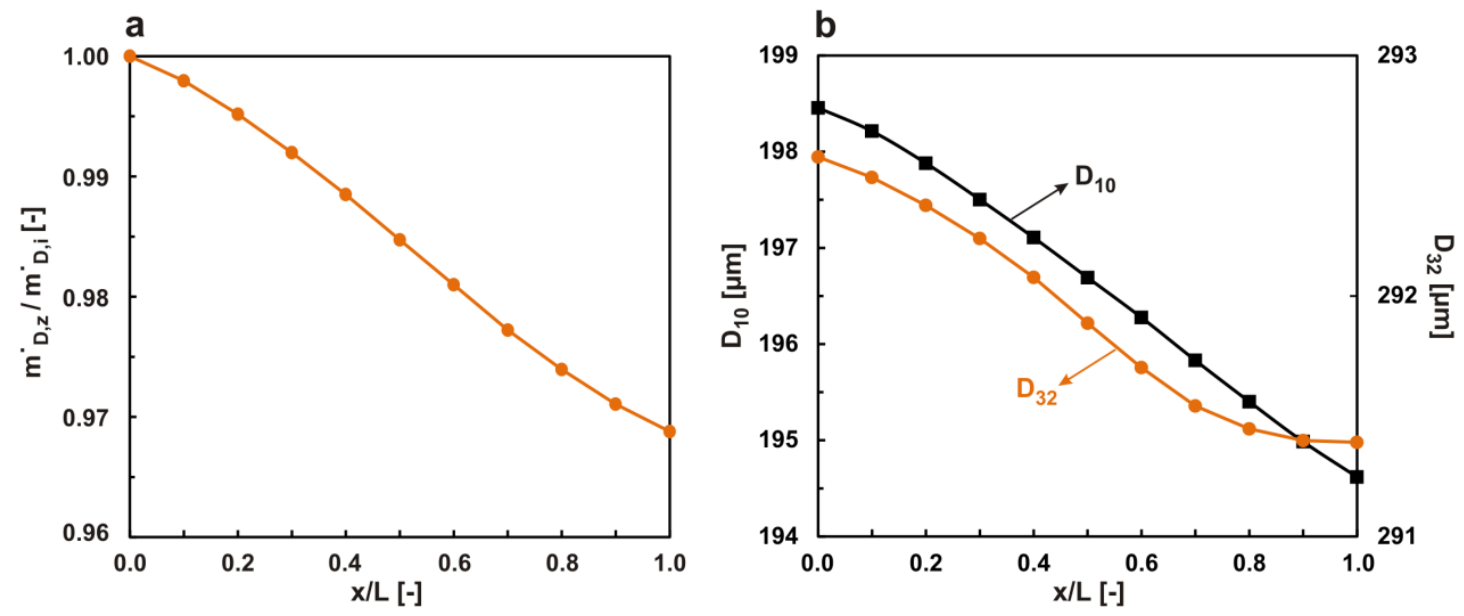

Figure 10. Profiles of (a) normalized droplet mass flow rate and (b) arithmetic $\left(D_{10}\right)$ and Sauter $\left(D_{32}\right)$ mean diameters along the domain for case 3 . 

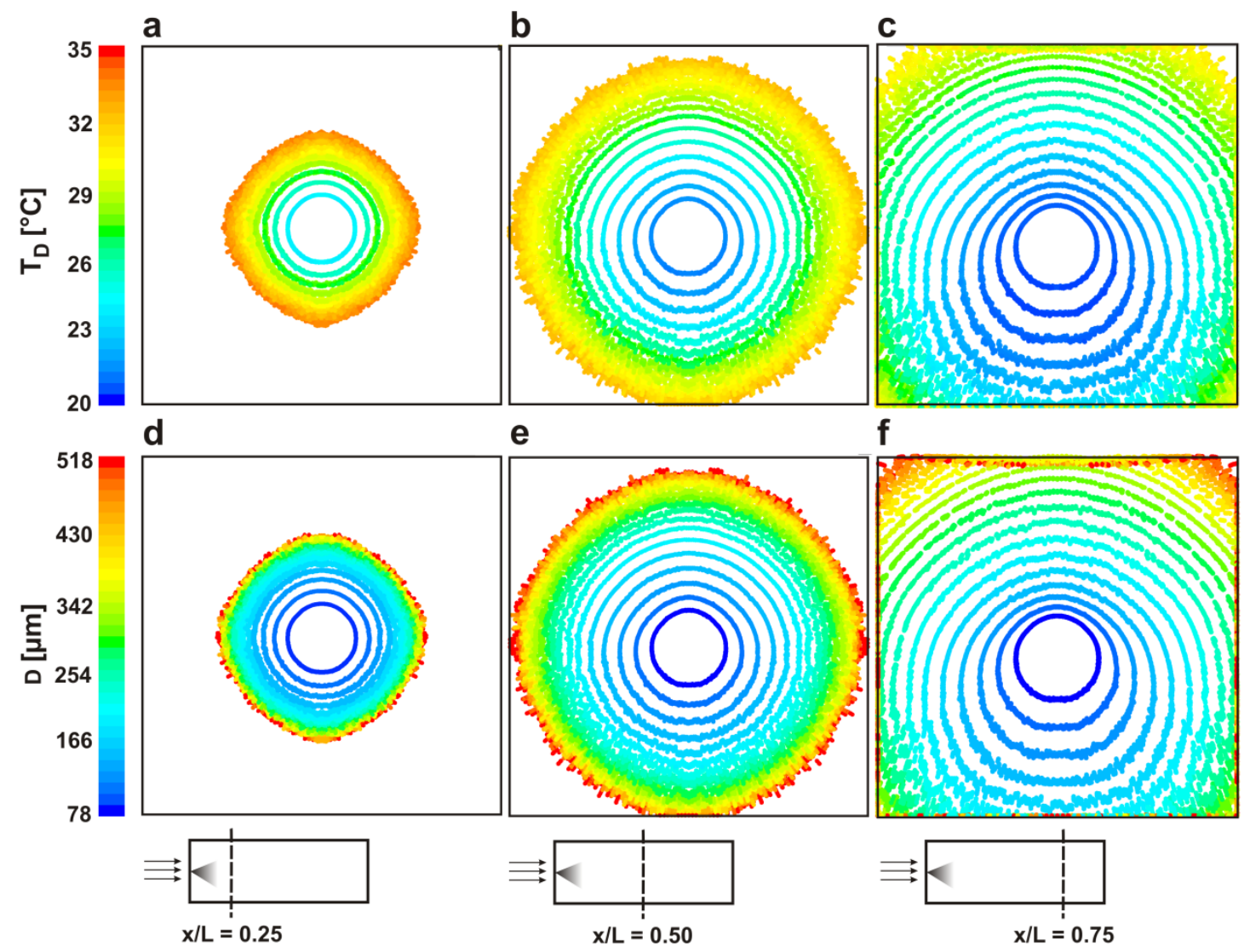

Figure 11. Droplet temperature distribution along the domain for three cross sections: (a) $\mathrm{x} / \mathrm{L}=0.25$, (a) $\mathrm{x} / \mathrm{L}=0.50$, (a) $\mathrm{x} / \mathrm{L}=0.75$. (d-f) same for droplet diameter distribution.

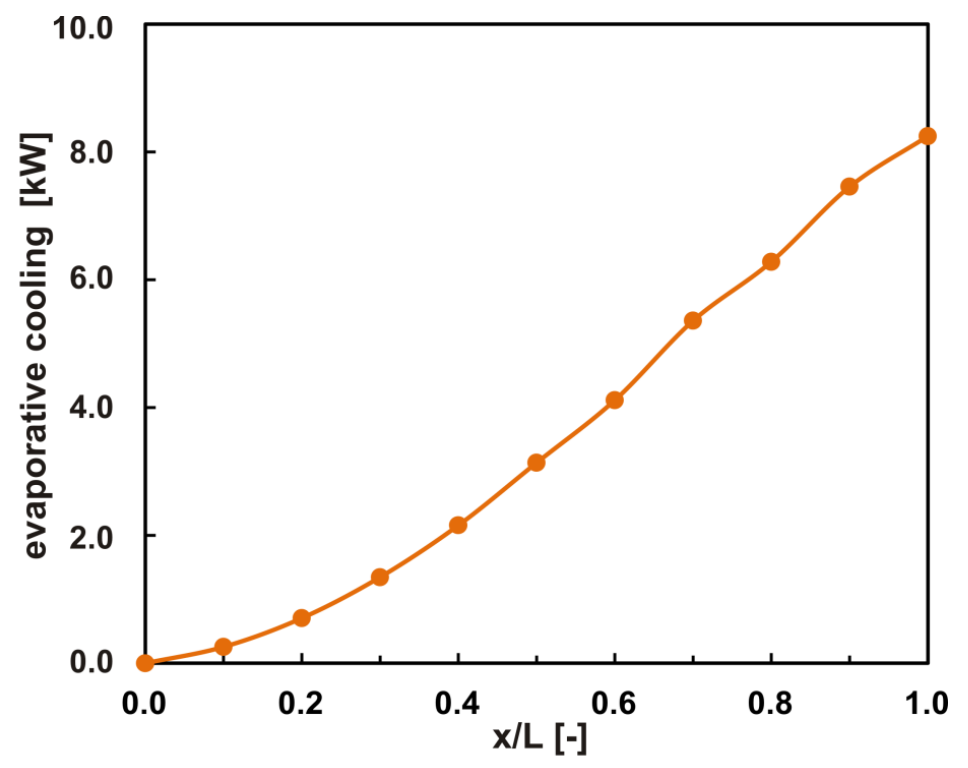

Figure 12. Profile of evaporative cooling capacity along the domain for case 3. 

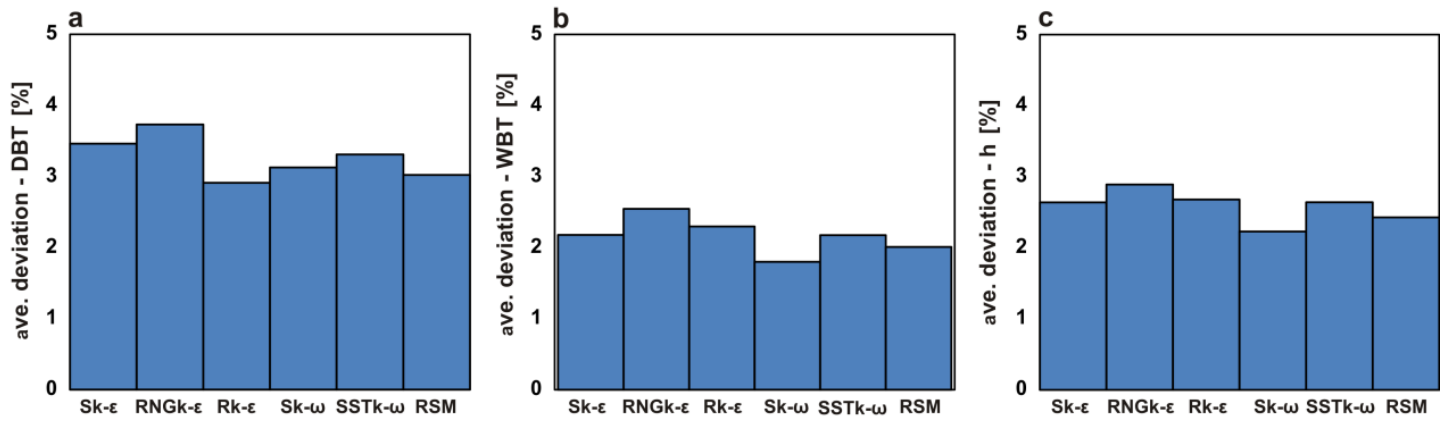

Figure 13. Impact of turbulence model on CFD simulation results of (a) DBT, (b) WBT and (c) specific enthalpy at the outlet plane (nine measurement points).
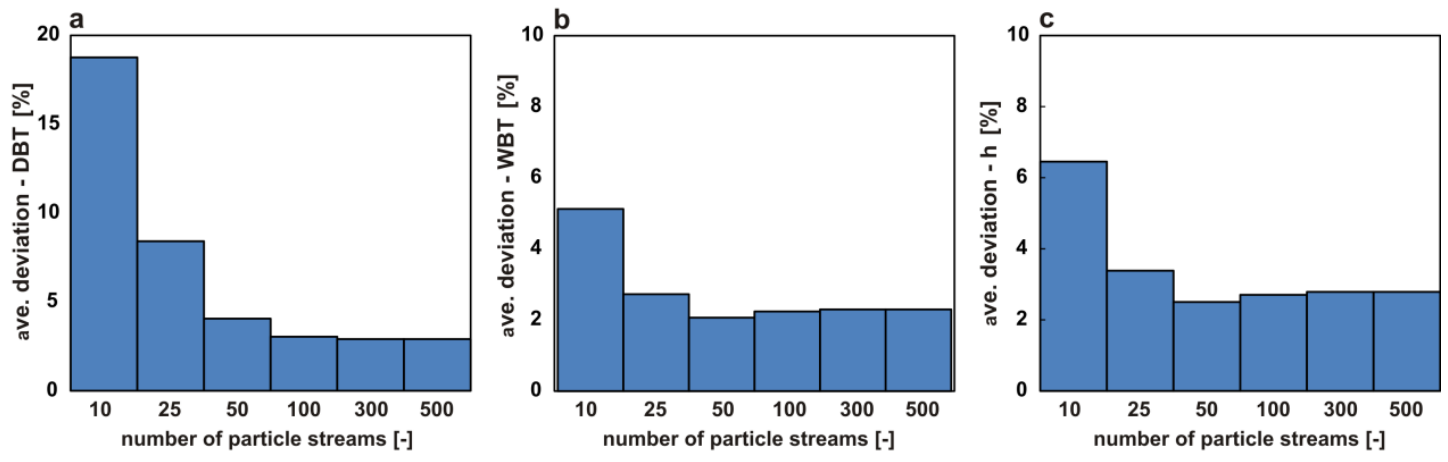

Figure 14. Impact of number of particle streams on CFD simulation results of (a) DBT, (b) WBT and (c) specific enthalpy at the outlet plane (nine measurement points).
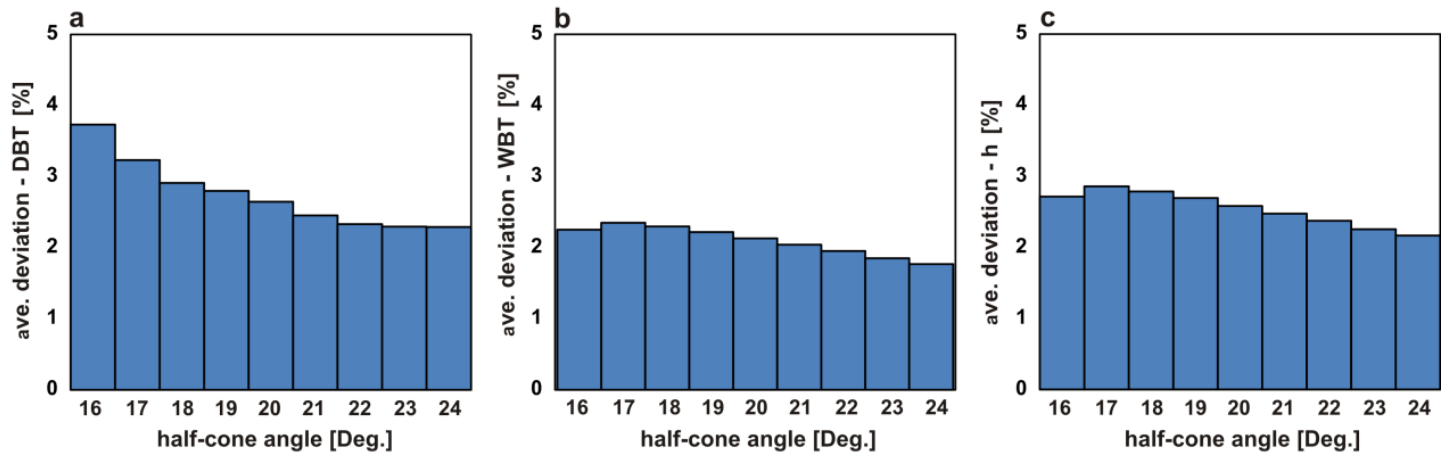

Figure 15. Impact of cone angle on CFD simulation results of (a) DBT, (b) WBT and (c) specific enthalpy at the outlet plane (nine measurement points). 


\section{TABLES}

Table 1. Drag coefficient model constants for different Reynolds numbers [75].

\begin{tabular}{cccc}
\hline Re range & $\mathbf{K}_{\mathbf{1}}$ & $\mathbf{K}_{\mathbf{2}}$ & $\mathbf{K}_{\mathbf{3}}$ \\
\hline $\operatorname{Re}<0.1$ & 24.00 & 0.00 & 0.00 \\
$0.1<\operatorname{Re}<1$ & 22.73 & 0.09 & 3.69 \\
$1<\operatorname{Re}<10$ & 29.17 & -3.89 & 1.22 \\
$10<\operatorname{Re}<100$ & 46.50 & -116.67 & 0.62 \\
$100<\operatorname{Re}<1000$ & 98.33 & -2778.00 & 0.36 \\
$1000<\operatorname{Re}<5000$ & 148.62 & -47500.00 & 0.36 \\
$5000<\operatorname{Re}<10000$ & -490.546 & 578700.00 & 0.46 \\
$10000<\operatorname{Re}<50000$ & -1662.50 & 5416700.00 & 0.52 \\
\hline
\end{tabular}

Table 2. List of some main parameters of the cases.

\begin{tabular}{cccccccccccc}
\hline \multirow{2}{*}{ case } & \multicolumn{3}{c}{ Inlet air } & \multicolumn{1}{c}{ Water } & \multicolumn{2}{c}{ Spray nozzle } \\
\cline { 2 - 10 } & $\begin{array}{c}\mathbf{V} \\
(\mathbf{m} / \mathbf{s})\end{array}$ & $\begin{array}{c}\mathbf{D B T} \\
\left({ }^{\circ} \mathbf{C}\right)\end{array}$ & $\begin{array}{c}\mathbf{W B T} \\
\left({ }^{\circ} \mathbf{C}\right)\end{array}$ & $\begin{array}{c}\mathbf{P} \\
(\mathbf{b a r})\end{array}$ & $\begin{array}{c}\mathbf{T}_{\text {in }} \\
\left({ }^{\circ} \mathbf{C}\right)\end{array}$ & $\begin{array}{c}\mathbf{T}_{\text {out }} \\
\left({ }^{\circ} \mathbf{C}\right)\end{array}$ & $\begin{array}{c}\dot{\boldsymbol{m}} \\
(\mathbf{l i t} / \mathbf{m i n})\end{array}$ & $\begin{array}{c}\mathbf{D} \\
(\mathbf{m m})\end{array}$ & $\boldsymbol{\alpha}(\mathbf{d e g})$ \\
\hline 1 & 1 & 41.4 & 18.9 & 3 & 35.1 & 25.3 & 12.5 & 4.0 & 22.0 \\
\hline 2 & 2 & 39.1 & 18.5 & 3 & 35.0 & 25.2 & 12.5 & 4.0 & 20.0 \\
\hline 3 & 3 & 39.2 & 18.7 & 3 & 35.2 & 26.1 & 12.5 & 4.0 & 18.0 \\
\hline
\end{tabular}

